\title{
Efeito do sortimento da madeira na produtividade e custo do forwarder no desbaste comercial de Pinus taeda
}

\author{
Wood assortment effect on productivity and \\ forwarder cost in commercial thinning of Pinus taeda
}

\author{
Eduardo da Silva Lopes ${ }^{1}$, Carlos César Cavassin Diniz ${ }^{2}$, \\ Edson Luís Serpe ${ }^{3}$ e Oscar Manuel de Jesús Veras Cabral ${ }^{4}$
}

\begin{abstract}
Resumo
Esta pesquisa objetivou avaliar o efeito do sortimento da madeira na produtividade e custo do forwarder na operação de extração em povoamentos de pinus submetidos ao regime de desbaste comercial. A pesquisa foi desenvolvida em uma empresa florestal no estado do Paraná, em povoamentos de Pinus taeda com 10 anos de idade submetidos ao primeiro desbaste. Foi estudada a operação de extração da madeira com o forwarder realizada por meio de dois modelos operacionais: (1) extração simultânea dos dois sortimentos destinadas para celulose e laminação dentro do mesmo ciclo operacional e posterior separação da madeira na margem da estrada; e (2) extração de um único tipo de sortimento por ciclo operacional e descarregamento na margem da estrada. A análise técnica englobou um estudo de tempos e movimentos pelo método contínuo para determinação da eficiência operacional, produtividade e consumo energético. A análise de custos englobou os parâmetros do custo operacional e de produção dos modelos de extração da madeira. Os resultados mostraram que a eficiência operacional média do forwarder foi de $62 \%$ em ambos os modelos de extração ocasionada pelas interrupções mecânicas. A produtividade média do forwarder nos procedimentos operacionais 1 e 2 foi de 13,5 e $15,9 \mathrm{~m}^{3} \mathrm{~h}^{-1}$, respectivamente, com diferença significativa $(\mathrm{P}<0,05)$. $\mathrm{O}$ modelo de extração proposto permitiu um ganho de produtividade e redução de custo de produção da ordem de $15 \%$, demonstrando ser um procedimento viável a ser utilizado em povoamentos florestais submetidos em regime desbaste.
\end{abstract}

Palavras-chave: Colheita de madeira; produtividade; custos; manejo florestal.

\begin{abstract}
The objective of this research was to evaluate the effect of the wood assortments on forwarder productivity and cost of the extraction operation in pinus stands submitted the commercial thinning. The research was carried out in a forest company, located in Parana State, Brazil, in a 10 years old stand of Pinus taeda submitted to its first thinning. The wood extraction operation with forwarder through two operational models was studied: (1) simultaneous extraction of two wood assortments for cellulose and bole within the same operational cycle and subsequent piling of wood separately next the roadside; and (2) extraction of a same wood assortment within the same operational cycle and unloading of wood on the roadside. The technical analysis included a movement and timing study by continuous method to determine the operational efficiency, productivity and energy consumption. The cost analysis included operational and production costs parameters in operational models of wood extraction. The results showed that the operational efficiency of the forwarder was $62 \%$ in both extraction wood models, caused mainly by mechanical interruption. The average productivity of the forwarder in the operational models 1 and 2 was 13.5 and $15.9 \mathrm{~m}^{3} \mathrm{~h}-1$, respectively, with significant difference $(P<0.05)$. The new extraction model allowed an increase of productivity and reduction of production cost by about $15 \%$, indicating this procedure to be more viable in forest stands subjected to thinning regime.
\end{abstract}

Keywords: Wood harvesting; productivity; costs; forest management.

\footnotetext{
${ }^{1}$ Professor Associado do Departamento de Ciências Florestais. UNICENTRO - Universidade Estadual do Centro-Oeste. PR 153, KM 7 - Cx. Postal 21 - Riozinho - 84500000 - Irati, PR, Brazil. E-mail: eslopes@irati.unicentro.br

${ }^{2}$ Engenheiro Florestal. UNICENTRO - Universidade Estadual do Centro-Oeste / Departamento de Ciências Florestais . PR 153, KM 7 - Cx. Postal 21 - Riozinho - 84500000 - Irati, PR, Brazil. E-mail: carloscezardiniz@gmail.com

${ }^{3}$ Mestrando do Programa de Pós-Graduação em Ciências Florestais. UNICENTRO - Universidade Estadual do Centro-Oeste. PR 153, KM 7 - Cx. Postal 21 - Riozinho - 84500000 - Irati, PR, Brazil. E-mail: serpe@remasa.com.br

${ }^{4}$ Mestre. Professor de Colheita Florestal. Universidade Nacional do Paraguai / Faculdade de Ciências Agrárias. Assunção, Paraguay. E-mail: oscarveracabral@gmail.com
} 
Lopes et al. - Efeito do sortimento da madeira na produtividade

e custo do forwarder no desbaste comercial de Pinus taeda

\section{INTRODUÇÃO}

O desbaste é um dos tratamentos silviculturais mais importantes no manejo de florestas plantadas destinadas à produção de madeira. Consiste na eliminação planejada, racional e criteriosa de parte das árvores de um povoamento (DAVEL, 2009; RIBEIRO et al., 2002), permitindo a regulação da competição entre as árvores e a melhor distribuição dos fatores de crescimento, como água, luz e nutrientes, e consequentemente, resultando na produção de árvores com maior valor agregado em termos de produção, qualidade e diversidade de usos da madeira (FINGER; SCHNEIDER, 1999).

Segundo Lamprech (1990), o desbaste não tem por objetivo apenas a seleção orientada dos melhores indivíduos qualitativamente, mas também uma regulagem próxima do espaçamento entre as árvores, de maneira a reduzir a concorrência indesejada. Além disso, objetiva concentrar no produto as caraterísticas desejadas pelo consumidor, sendo que o padrão procurado é o tamanho dos troncos (diâmetro, comprimento), a forma e qualidade tecnológica da madeira.

Em relação ao aspecto operacional, a necessidade de eliminar algumas árvores de um povoamento por meio dos desbastes mecanizado é uma atividade de grande complexidade e onerosa em termos econômicos, pois as operações são realizadas pelas máquinas em espaços restritos dentro do povoamento, acarretando em baixa produtividade operacional e elevados custos de produção.

Spinelli e Nati (2009) citam que a grande dificuldade em mecanizar as operações de desbastes se deve ao fato das árvores remanescentes do povoamento limitarem a mobilidade das máquinas no interior do povoamento, sendo o tipo de máquina a ser utilizado um dos fatores de maior influência na execução da operação (SPINELLI, 2004; LAGESON, 1997). Já Belbo (2008) cita que os elevados custos da colheita de madeira são os principais problemas enfrentados na execução dos desbastes, sendo diretamente afetados pela baixa produtividade das máquinas, elevados custos de produção e baixo valor dos produtos colhidos.

Wadsworth (2000) menciona que a mecanização das operações de desbaste depende das características do terreno e da disposição do plantio, de modo a permitir a operação das máquinas entre as fileiras de árvores em menores distâncias de extração e com a presença de grandes volumes de madeira por unidade de área. Já Silva et al. (2010) relatam que a produtividade das máquinas é influenciada pela densidade do povoamento, altura das árvores e relação entre a altura e o diâmetro, enquanto Mederski (2006) afirma que a baixa produtividade das máquinas ocorre devido ao tamanho e distribuição irregular das árvores no povoamento.

O uso do trator florestal forwarder é muito comum na extração de madeira, tanto no regime de corte raso quanto em desbastes. Trata-se de uma máquina articulada, com tração 4x4, 6x6 ou 8x8, possuindo uma plataforma com capacidade de carga de 10 a 20 toneladas e uma grua hidráulica de alcance máximo de 6,8 a 7,8 m, equipada com rodados de pneus ou esteiras, sendo capaz de executar as operações no interior do povoamento, retirando a madeira para a margem da estrada ou pátio intermediário, na forma de "baldeio" (SEIXAS, 2014).

A operação de extração de madeira no regime de desbaste pode ser afetada por diversos fatores, como o nível de experiência e habilidade dos operadores, capacidade de carga da máquina, distância de extração, número de linhas e características das trilhas de extração, comprimento das toras, volume dos feixes de toras, alcance da lança hidráulica e área da garra da máquina e tempo do ciclo de operação (Seixas, 2014; Silva e Fenner, 2009; Oliveira et al., 2009). Malinovski et al. (2006) citam ainda a influencia do sortimento da madeira devido à necessidade de ordenamento das toras, de possíveis viagens adicionais e pela não ocupação total da área útil de carga da garra da máquina no momento do carregamento.

Oliveira et al. (2009) estudando a extração de madeira de pinus com diferentes sortimentos em regime de corte raso, verificaram que a extração por classe de sortimento e a dispersão das pilhas de toras no interior do talhão influenciou negativamente no desempenho e na baixa eficiência operacional do forwarder. Os autores sugerem ainda o agrupamento das toras e posterior separação na margem da estrada para obtenção de maior eficiência, entretanto, não existem relatos de como deveria ser realizado esta operação com toras de diferentes sortimentos na colheita de madeira em povoamento submetidos ao regime de desbaste.

Diante disso, esta pesquisa objetivou realizar uma análise da produtividade e do custo do forwarder na extração de toras com diferentes sortimentos em povoamento de Pinus taeda submetido ao 
regime de desbaste, visando gerar informações para auxiliar o planejamento das operações e o melhor aproveitamento dos recursos.

\section{MATERIAL E MÉTODOS}

\section{Descrição da área de estudo}

A pesquisa foi realizada nas áreas de colheita da madeira da empresa Remasa Reflorestadora, localizada no município de Bituruna, Sul do estado do Paraná, entre as coordenadas geográficas de Latitude $26^{\circ} 09^{\prime} 41^{\prime \prime} \mathrm{S}$ e Longitude $51^{\circ} 33^{\prime} 09^{\prime \prime} \mathrm{W}$.

O clima predominante na região de estudo é classificado como "subtropical úmido mesotérmico" (Cfb), caracterizado por verão fresco e inverno rigoroso, com geadas severas e freqüentes entre os meses de março e setembro, não apresentando estação seca característica, com temperatura média variando entre 18 e $22^{\circ} \mathrm{C}$. O solo predominante da região é o cambissolo, com relevo classificado como plano a ondulado e altitude média de 987 metros.

O experimento foi conduzido em um povoamento de Pinus taeda com idade de 10 anos, submetido ao primeiro desbaste, em uma área total de cinco hectares. O desbaste foi realizado pelo método combinado, ou seja, desbaste sistemático e seletivo. Neste método houve a eliminação das $5^{\text {a }}$ linhas do plantio realizada de forma sistemática, de modo a permitir a entrada das máquinas no interior do povoamento, com remoção de $20 \%$ das árvores, bem como eliminação das demais linhas do povoamento de forma seletiva, com remoção de $30 \%$ das árvores, perfazendo uma remoção total de 50\% das árvores, equivalente em torno de 630 árvores por hectare.

As árvores removidas foram processadas no interior do povoamento em toras com duas classes de sortimentos: a) toras destinadas para celulose com diâmetro de 8 a $16 \mathrm{~cm}$ e comprimento de 2,40 $\mathrm{m}, \mathrm{e}$ b) toras destinadas para laminação com diâmetro acima de $16 \mathrm{~cm}$ e comprimento de 2,65 m.

As características do povoamento estudado são apresentadas na Tabela 1.

Tabela 1. Caracterização da área de estudo.

Table 1. Characterization of the study area.

\begin{tabular}{lc}
\hline Descrição & Valores \\
\hline Espécie & Pinus taeda L. \\
Declividade do terreno (graus) & 0 a 15 \\
Idade do povoamento (anos) & 10 \\
Densidade do povoamento $($ árv. ha-1 $)$ & 1.260 \\
Área basal do povoamento $\left(\mathrm{m}^{2} \cdot \mathrm{ha}^{-1}\right)$ & 46,24 \\
Diâmetro médio das árvores, DAP $(\mathrm{cm})$ & 21,32 \\
Altura média das árvores $(\mathrm{cm})$ & 15,49 \\
Volume médio individual das árvores $\left(\mathrm{m}^{3}\right)$ & 0,2733 \\
Volume médio toras celulose $\left(\mathrm{m}^{3}\right)$ & 0,030 \\
Volume médio toras laminação $\left(\mathrm{m}^{3}\right)$ & 0,080 \\
Volume total $\left(\mathrm{m}^{3}\right.$.ha-1 $)$ & 338,24 \\
\hline
\end{tabular}

\section{Definição dos modelos operacionais}

A empresa utilizava na execução do desbaste mecanizado o sistema de colheita de madeira de toras curtas (cut-to-length), onde a derrubada das árvores e processamento da madeira foi realizado por um trator florestal harvester, da marca Caterpillar, modelo 315, equipado com cabeçote Logmax 5000. A extração da madeira do interior do povoamento para a margem da estrada foi realizada por um trator florestal forwarder, da marca Komatsu, modelo 865, com motor de $212 \mathrm{hp}$ ou 158,0 kw de potência, capacidade de carga de $15.000 \mathrm{~kg}$, alcance da grua de 7,8 m.

Neste estudo avaliou-se a operação de extração das toras na forma de "baldeio" no regime de desbaste por meio de dois modelos operacionais (Figura 1):

(a) Modelo operacional 1: Extração simultânea dos dois tipos de sortimentos de toras destinadas para celulose e laminação dentro do mesmo ciclo operacional, com posterior separação das toras na margem da estrada durante o descarregamento.

(b) Modelo operacional 2: Extração de um único tipo de sortimento de tora por ciclo operacional, com posterior descarregamento na margem da estrada. 

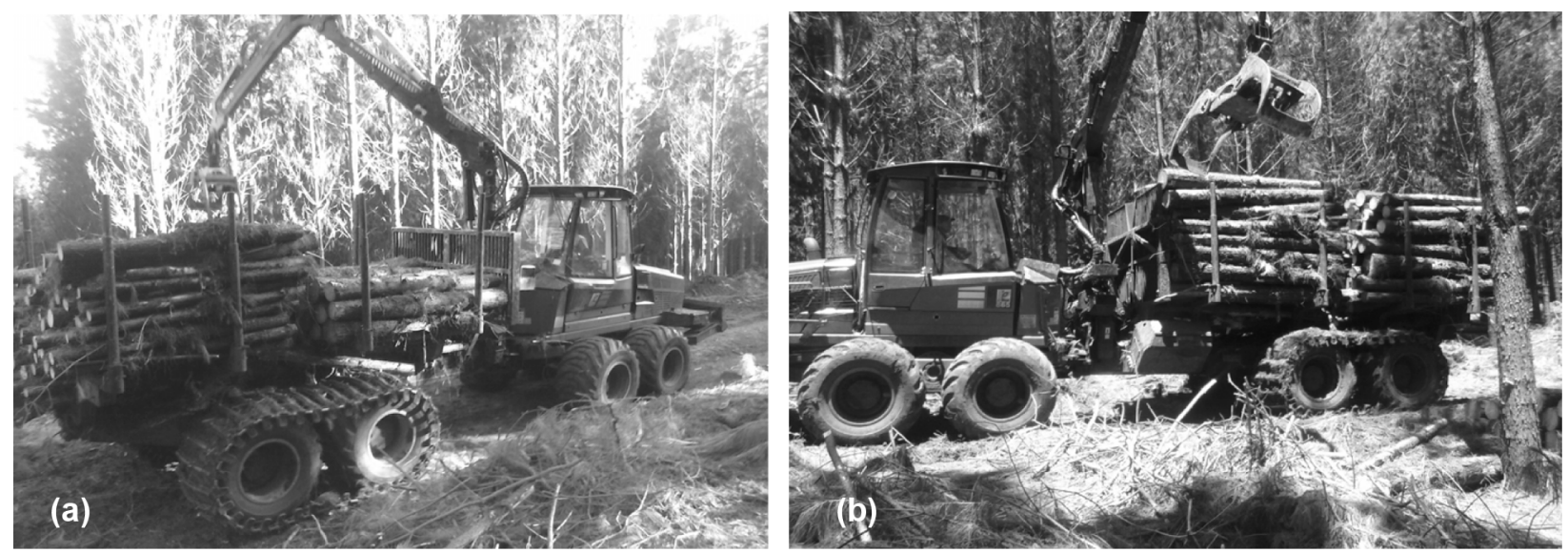

Figura 1. Extração de madeira com forwarder nos modelos operacionais de extração 1(a) e 2 (b).

Figure 1. Extraction of wood with forwarder in in the extraction operational models 1(a) and 2(b).

A área experimental foi composta por um talhão com condições homogêneas em relação às características do povoamento, solo, relevo, clima e máquina. Foi ainda utilizado o mesmo operador com experiência para execução de ambos os modelos de extração. Além disso, procedeu-se a extração da madeira nos dois modelos de extração em dias alternados, permitindo controlar a coleta e homogeneidade dos dados durante o estudo.

\section{Estudo de tempos e movimentos}

No estudo do ciclo operacional do forwarder na extração da madeira em ambos os modelos operacionais foi utilizado o método de cronometragem de tempos contínuos, com uso de cronômetro centesimal, prancheta e formulários de campo específicos. Inicialmente foi realizado um estudo-piloto, a fim de estimar estatisticamente o número mínimo de ciclos operacionais, sendo utilizada a metodologia proposta por Barnes (1977), de modo a proporcionar um erro de amostragem máximo de $5 \%$ a $95 \%$ de confiança por meio da seguinte expressão:

$$
\mathrm{n} \geq \frac{\mathrm{t}^{2} \times C V^{2}}{\mathrm{E}^{2}}
$$

Em que: $\mathrm{n}=$ número mínimo de ciclos operacionais necessários; $\mathrm{t}=$ valor de " $\mathrm{t}$ " de Student, para o nível de probabilidade desejado e (n-1) graus de liberdade; e CV = coeficiente de variação da amostra (\%) e; E = erro admissível (\%).

O ciclo operacional do forwarder na extração da madeira foi subdividido nas seguintes atividades parciais: Viagem Vazio (VV) - tempo compreendido pelo deslocamento da máquina da margem da estrada até a primeira pilha de toras no interior do talhão; Carregamento (CR) - tempo compreendido pela movimentação da grua da máquina para realização do carregamento das toras até o posicionamento da grua sobre a caixa de carga após finalizado o carregamento; Viagem Entre Carga (VEC) - tempo compreendido pelos deslocamentos da máquina na trilha de extração entre as pilhas de toras a serem carregadas; Viagem Carregado (VC) - tempo compreendido pelo início do deslocamento da máquina no interior do talhão até a pilha de toras localizadas na margem da estrada; Descarregamento (DC) - tempo compreendido pela movimentação da grua para realização do descarregamento das toras até o posicionamento da grua sobre a caixa de carga da máquina vazia após concluído o descarregamento; e Interrupções (INT) - tempo compreendido em que a máquina não estava realizando as atividades anteriores.

\section{Disponibilidade mecânica, eficiência operacional, produtividade e rendimento energético}

A disponibilidade mecânica foi definida como o percentual do tempo em que a máquina estava apta a realizar o trabalho produtivo, desconsiderando-se o tempo em manutenção preventiva e corretiva, determinada pela seguinte equação: 


$$
\mathrm{DM}=\frac{\mathrm{TP}-\mathrm{TM}}{\mathrm{TP}} \times 100
$$

Em que: DM = grau de disponibilidade mecânica (\%); TP = tempo programado para o trabalho (horas); $\mathrm{TM}=$ tempo de manutenção preventiva e corretiva (horas); e

A eficiência operacional foi definida pelo percentual do tempo efetivamente trabalhado em relação ao tempo programado, determinada pela seguinte equação:

$$
E O=\frac{T E}{(T E+T I)} \times 100
$$

Em que: $\mathrm{EO}=$ eficiência operacional (\%); $\mathrm{TE}=$ tempo efetivo de trabalho (horas); $\mathrm{e} \mathrm{TI}=$ tempo de interrupções operacionais e não operacionais (horas).

A produtividade da máquina foi determinada, em metros cúbicos com casca por hora de trabalho, sendo obtida por meio do número de toras extraídas por ciclo operacional, sendo então multiplicado pelo volume médio das toras e dividido pelas horas efetivamente trabalhadas, conforme a seguinte expressão:

$$
\mathrm{PR}=\frac{\mathrm{N} \times \mathrm{V}}{\mathrm{HE}}
$$

Em que: $\mathrm{PR}=$ Produtividade $\left(\mathrm{m}^{3} \mathrm{cc} \mathrm{h} \mathrm{h}^{-1}\right) ; \mathrm{N}=$ número de árvores extraídas; $\mathrm{V}=$ volume médio individual das toras com casca; $\left(\mathrm{m}^{3} \mathrm{cc}\right)$; e $\mathrm{HE}=$ tempo efetivo de trabalho (horas).

O rendimento energético, que indica a massa de combustível necessária para produzir uma unidade de potência na unidade de tempo, foi obtida pela razão entre o consumo específico efetivo de combustível, em gramas para cada kilowatts fornecido durante uma hora e a produtividade média com casca da máquina (LOPES, 2007 citado por SIMÕES et al., 2010), conforme a seguinte equação:

$$
\mathrm{RE}=\frac{\mathrm{CE}}{\mathrm{Pr}}
$$

Em que: $\mathrm{RE}=$ rendimento energético $\left(\mathrm{g} \mathrm{kW}^{-1} \mathrm{~m}^{-3} \mathrm{cc}\right) ; \mathrm{CE}=$ consumo específico de combustível $(\mathrm{g}$ $\left.\mathrm{kW}^{-1} \mathrm{he}^{-1}\right)$; e $\operatorname{Pr}=$ produtividade $\left(\mathrm{m}^{3} \mathrm{cc} \mathrm{he} \mathrm{e}^{-1}\right)$.

O consumo específico de combustível expressa o consumo de combustível por unidade de potência nominal do trator, foi obtida pela multiplicação da densidade do combustível ( $\left.\mathrm{g} \mathrm{L}^{-1}\right)$ pelo consumo de combustível da máquina por hora efetiva $\left(L \mathrm{~L} \mathrm{he}^{-1}\right)$ e dividido pela potência nominal da máquina $(\mathrm{kW})$, conforme a equação:

$$
\mathrm{CE}=\frac{\mathrm{D} \times \mathrm{C}}{\mathrm{Pt}}
$$

Em que: $\mathrm{CE}=$ consumo específico de combustível $\left(\mathrm{g} \mathrm{kW}^{-1} \mathrm{he} \mathrm{e}^{-1}\right) ; \mathrm{D}=$ densidade do combustível ( $\mathrm{g}$ $\left.\mathrm{L}^{-1}\right)$, sendo considerado $0,85 \mathrm{~g} \mathrm{~L}^{-1}$ para diesel; $\mathrm{C}=$ consumo de combustível por hora efetiva $\left(\mathrm{L} \mathrm{he}^{-1}\right)$ $\mathrm{e} ; \mathrm{Pt}=$ potência nominal do trator $(\mathrm{kW})$.

\section{Determinação dos custos operacionais e de produção}

A análise de custos do forwarder foi realizada com base no custo operacional e de produção, conforme metodologias específicas desenvolvidas para máquinas florestais. O custo operacional foi determinado pelo método contábil conforme metodologia proposta por Miyata (1980) e Lopes (2001), englobando os custos fixos (depreciação, juros e seguros), custos variáveis (combustíveis, lubrificantes e graxas, óleo hidráulico, pneus, manutenção e reparos e transporte de pessoal) e os custos de pessoal (salário e encargos sociais). O custo de produção foi obtido pela divisão dos custos operacionais $\left(\mathrm{R} \$ \mathrm{he}^{-1}\right)$ pela produtividade $\left(\mathrm{m}^{3} \mathrm{he}^{-1}\right)$.

\section{Análise estatística}

Foi aplicado o teste F (amostras independentes) para testar a homogeneidade das variâncias dentro de cada modelo operacional de extração. Em seguida, aplicou-se para os resultados das vari- 
áveis homogêneas o teste $\mathrm{T}$, caso 1 (duas amostras presumindo variâncias equivalentes), de forma a testar a diferença dos tempos médios dos ciclos operacionais em ambos os modelos de extração. Os dados das variáveis heterogêneas foram comparados pelo teste T de Student, caso 2 (duas amostras presumindo variâncias diferentes), ao nível de $5 \%$ de probabilidade.

\section{RESULTADOS E DISCUSSÃO}

\section{Estudos de tempos e movimentos}

No estudo foi obtido um total de 94 ciclos operacionais de extração da madeira, atendendo à exigência mínima do estudo piloto de 63 ciclos, perfazendo um volume de madeira total extraído de $888 \mathrm{~m}^{3}$, na proporção de $62 \%$ para celulose e $38 \%$ para laminação.

Na Figura 2 é mostrada a distribuição percentual dos tempos das atividades parciais do forwarder na execução de ambos os modelos de extração. Como pode ser observado, a atividade parcial carregamento demandou o maior tempo percentual do ciclo operacional, com 52\% e 50\% do tempo total nos modelos 1 e 2, respectivamente. Tal resultado pode ser atribuído ao fato das toras estarem empilhadas entre as árvores remanescentes do povoamento, situação que normalmente em desbastes dificulta a localização das pilhas e o carregamento da madeira. Além disso, em função do baixo volume de madeira gerado pelo povoamento no primeiro desbaste, e consequentemente, do volume das pilhas de toras, a garra da máquina efetuava o carregamento não otimizando a sua capacidade máxima, contribuindo desta forma para a baixa eficiência operacional e o elevado tempo de carregamento.

\section{Modelo Operacional 1}

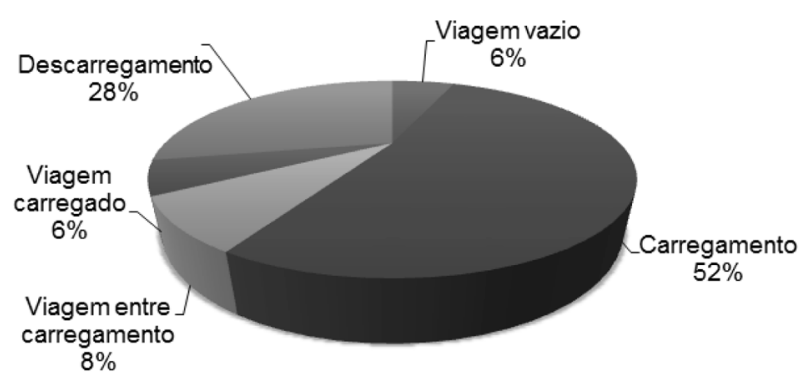

Modelo Operacional 2

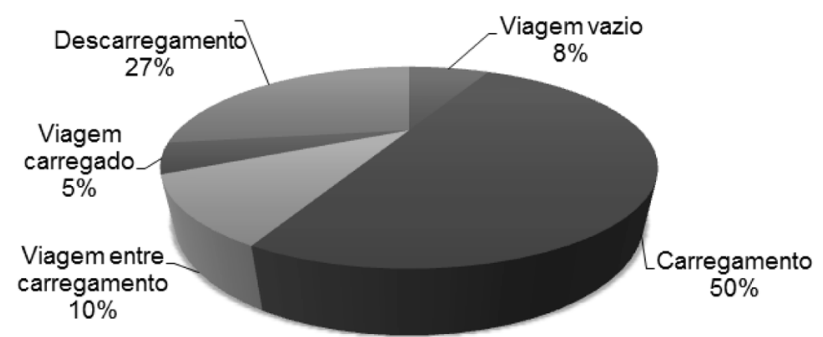

Figura 2. Distribuição dos tempos das atividades parciais do forwarder nos modelos operacionais de extração 1 e 2 . Figure 2. Distribution of times the partial activities of forwarder in the operational models 1 and 2.

É importante ainda ressaltar o elevado tempo consumido pelas atividades de carregamento e descarregamento, com valores médios de 80 e $77 \%$ do tempo total nos procedimentos operacionais 1 e 2, respectivamente. Tal resultado é semelhante ao obtido por diversos autores (Simões et al., 2010; Oliveira et al., 2009; Minette et al., 2004), que encontraram na operação de extração de madeira em corte raso um elevado tempo de carregamento e descarregamento, com 78,5\%; 78,0\%, $80,0 \%$ do tempo total, respectivamente.

Além disso, percebe-se um maior tempo consumido pela máquina nas viagens entre o carregamento no modelo operacional 2, explicado pelo fato de ser carregado apenas um tipo de sortimento, onde a máquina necessitava percorrer uma maior distância para apanhar as toras empilhadas ao longo da trilha de extração.

Ao comparar os modelos operacionais de extração, verificou-se que o menor tempo consumido pela máquina na execução do procedimento 2 foi ocasionado pelo menor tempo consumido para execução das etapas de carregamento e descarregamento da madeira, que foram as atividades parciais que ocuparam o maior tempo do ciclo operacional. É importante ainda ressaltar que, o menor tempo de descarregamento ocorreu devido a não necessidade de realização de manobras para separação dos sortimentos de toras na margem da estrada, situação muito comum no modelo 1 (Figura 3). 


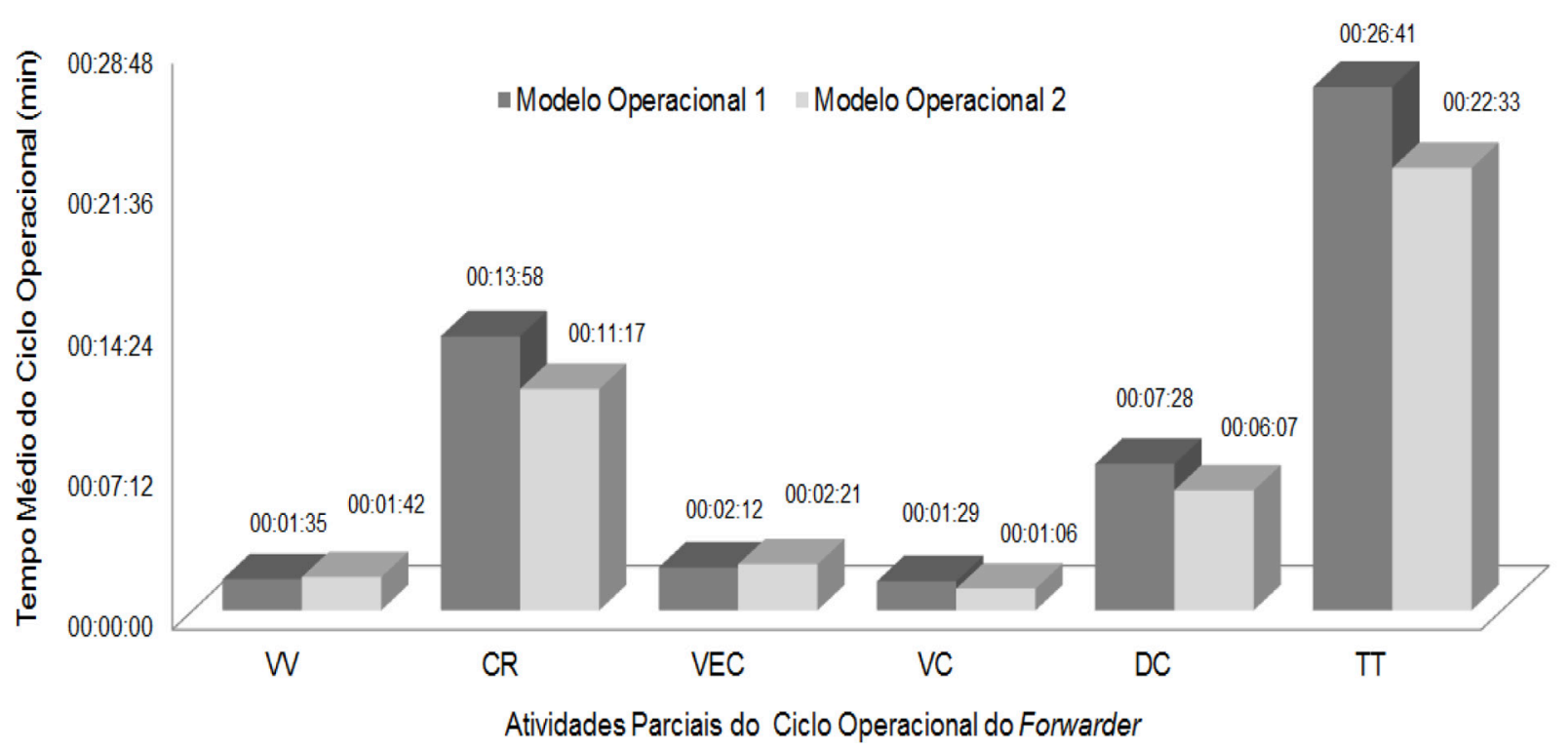

Em que: $\mathrm{W}=$ Viagem Vazio; $\mathrm{CR}=$ Carregamento $(\mathrm{CR}) ; \mathrm{VEC}=$ Viagem entre Carga; $\mathrm{VC}=$ Viagem Carregado, $\mathrm{DC}=\mathrm{Descarregamento}, \mathrm{TT}=$ Tempo Total.

Figura 3. Tempos médios das atividades parciais do forwarder nos modelos operacionais de extração 1 e 2.

Figure 3. Mean times of the partial activities of the forwarder in the operational models 1 and 2.

Em relação ao ciclo operacional da extração da madeira, verifica-se que, de modo geral, houve uma redução no tempo total médio no modelo operacional 2, onde o tempo médio de extração das toras com único sortimento foi de 22,6 minutos, enquanto na extração simultânea de diferentes sortimentos foi de 27,2 minutos, com diferença significativa $(\mathrm{P}<0,05)$, afetada pela redução dos tempos de carregamento e descarregamento.

As interrupções mecânicas causadas pela necessidade de realização de manutenção corretiva (29\%) e espera pelo mecânico (16\%) foram as principais causas da ineficiência operacional da máquina na execução da operação, demonstrando a necessidade de melhorias no planejamento operacional e de manutenção.

\section{Disponibilidade mecânica, eficiência operacional, produtividade e rendimento energético}

Na Tabela 2 é mostrado os resultados da disponibilidade mecânica, eficiência operacional, produtividade e rendimento energético do forwarder em ambos os modelos de extração das toras. Como pode ser visto, a disponibilidade mecânica média foi de $89 \%$ e a eficiência operacional média de $62 \%$, podendo ser consideradas baixas quando comparado aos valores obtidos por outros autores (Minette et al., 2004; Oliveira et al., 2009). Entretanto, os resultados mostram a necessidade do estabelecimento de algumas medidas para a otimização da operação, por meio de um melhor planejamento e controle das operações, principalmente em relação aos procedimentos de manutenção mecânica.

É importante ainda ressaltar que, considerando a eficiência operacional média de $62 \%$ em ambos os modelos operacionais de extração estudados em uma distância média de 100 m, obteve-se uma produtividade média do forwarder de 13,5 e 15,9 $\mathrm{m}^{3} \mathrm{~h}^{-1}$ nos modelos operacionais 1 e 2, respectivamente, com diferença significativa entre si $(\mathrm{P}<0,05)$.

A baixa produtividade da máquina na execução da extração da madeira no desbaste comparado ao corte raso pode ser explicada pelo fato de tratar-se de uma operação realizada em povoamento submetido ao primeiro desbaste, cujas árvores são de baixo volume individual e pela ineficiência operacional devido a não ocupação total da área útil de carga da garra no momento do carregamento. 
Lopes et al. - Efeito do sortimento da madeira na produtividade

e custo do forwarder no desbaste comercial de Pinus taeda

Tabela 2. Produtividade e rendimento energético do forwarder nos modelos operacionais de extração.

Table 2. Productivity and energy consumption rate of the forwarder in the extraction operational models.

\begin{tabular}{|c|c|c|c|c|}
\hline $\begin{array}{l}\text { Modelo } \\
\text { Operacional }\end{array}$ & $\begin{array}{c}\text { Disponibilidade } \\
\text { Mecânica Média (\%) }\end{array}$ & $\begin{array}{c}\text { Eficiência Operacional } \\
\text { Média (\%) }\end{array}$ & $\begin{array}{l}\text { Produtividade } \\
\left(\mathrm{m}^{3} \mathrm{cc} \mathrm{he} \mathrm{h}^{-1}\right)\end{array}$ & $\begin{array}{l}\text { Rendimento Energético } \\
\left(\mathrm{g} \mathrm{KW}^{-1} \mathrm{~m}^{3} \mathrm{cc}\right)\end{array}$ \\
\hline 1 & \multirow{2}{*}{89,0} & \multirow{2}{*}{62,0} & 13,5 & 6,38 \\
\hline 2 & & & 15,9 & 5,42 \\
\hline
\end{tabular}

Na Figura 4 é mostrado o comportamento da produtividade média do forwarder nos diferentes modelos e distâncias de extração. Como pode ser visto, o modelo de extração proposto apresentou as maiores produtividades, principalmente nas menores distâncias, podendo ser explicado pela maior agilidade da máquina na realização da extração de apenas um tipo de sortimento por ciclo operacional. Observa-se ainda que, em ambos os modelos operacionais, houve redução da produtividade com o aumento da distância de extração. Entretanto, a partir da distância de $125 \mathrm{~m}$, houve um aumento da produtividade da máquina em ambos os modelos operacionais, podendo ser explicado pelo fato de que, a partir deste ponto, o forwarder realizava a extração das toras num único sentido, ou seja, entrava por um lado do talhão efetuando o carregamento da madeira e descarregava do lado oposto.

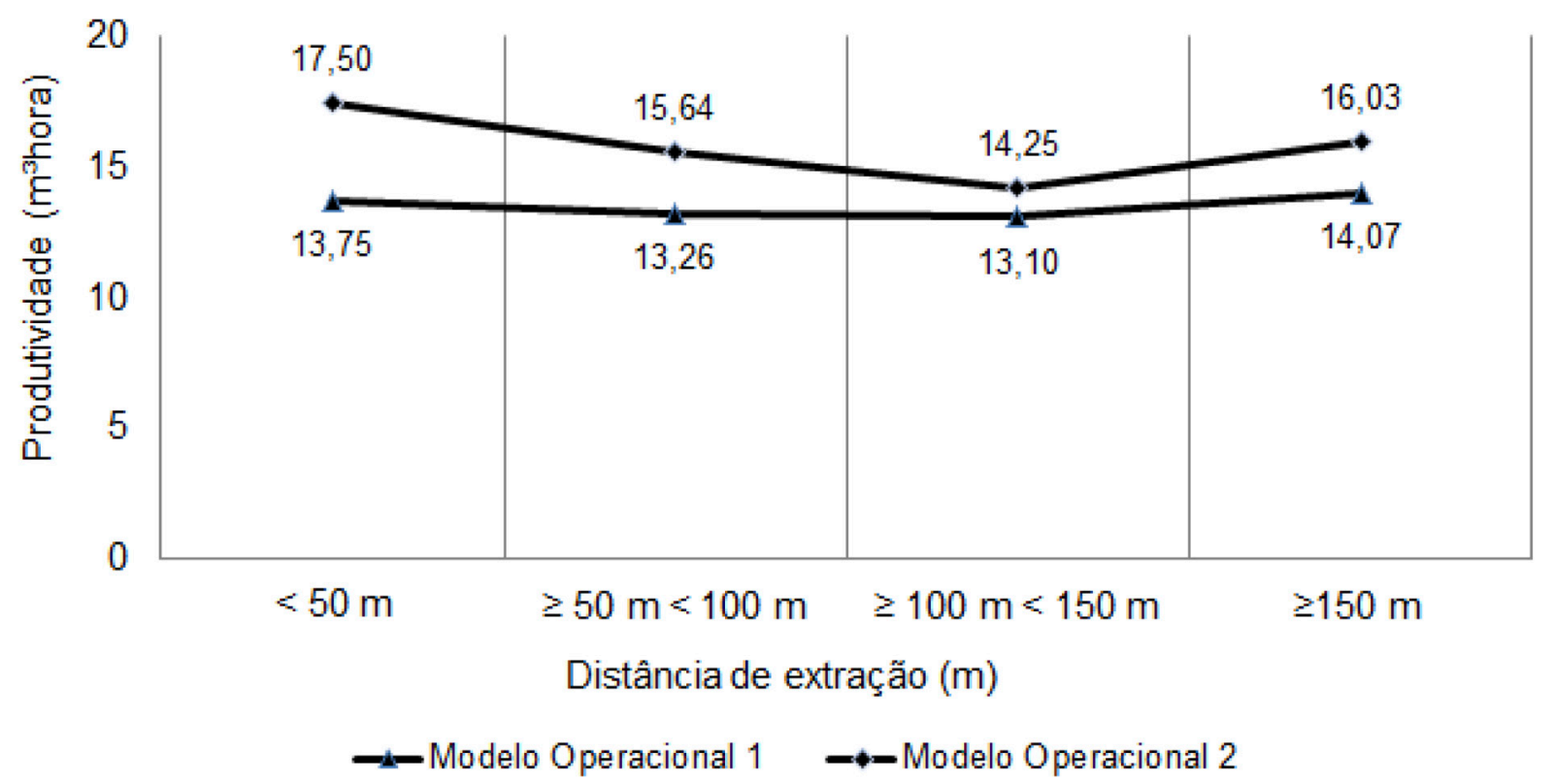

Figura 4. Produtividade média do forwarder nos diferentes modelos operacionais e distâncias de extração.

Figure 4. Mean productivity of the forwarder in the different operational models and extraction distances.

Em relação ao rendimento energético do forwarder na extração da madeira no regime de desbaste obteve-se 6,38 e 5,42 $\mathrm{g} \mathrm{kW}^{-1} \mathrm{~m}^{3} \mathrm{cc}$, considerando um consumo específico de combustível médio de $86,1 \mathrm{~g} \mathrm{~kW}^{-1}$.he $\mathrm{e}^{-1}$ e uma produtividade média de 13,5 e 15,9 $\mathrm{m}^{3} \mathrm{Cc} \mathrm{he}^{-1}$, nos modelos operacionais de extração 1 e 2 , respectivamente.

\section{Custo operacional e de produção}

Considerando-se uma taxa de juros de $8 \%$ ao ano, obteve-se um custo operacional total médio do forwarder por hora efetiva trabalhada de $\mathrm{R} \$ 158,55 \mathrm{he}^{-1}$. Como pode ser visto na Figura 5, o custo fixo (depreciação, juros e seguros e pessoal) corresponderam juntos, a 36\% dos custos operacionais totais. Os custos variáveis corresponderam a $44 \%$ dos custos totais, sendo afetados diretamente pelos custos de combustíveis $(17 \%)$, seguido pelos custos de manutenções e reparos (10\%), enquanto os custos de pessoal corresponderam a $20 \%$ dos custos operacionais totais. 


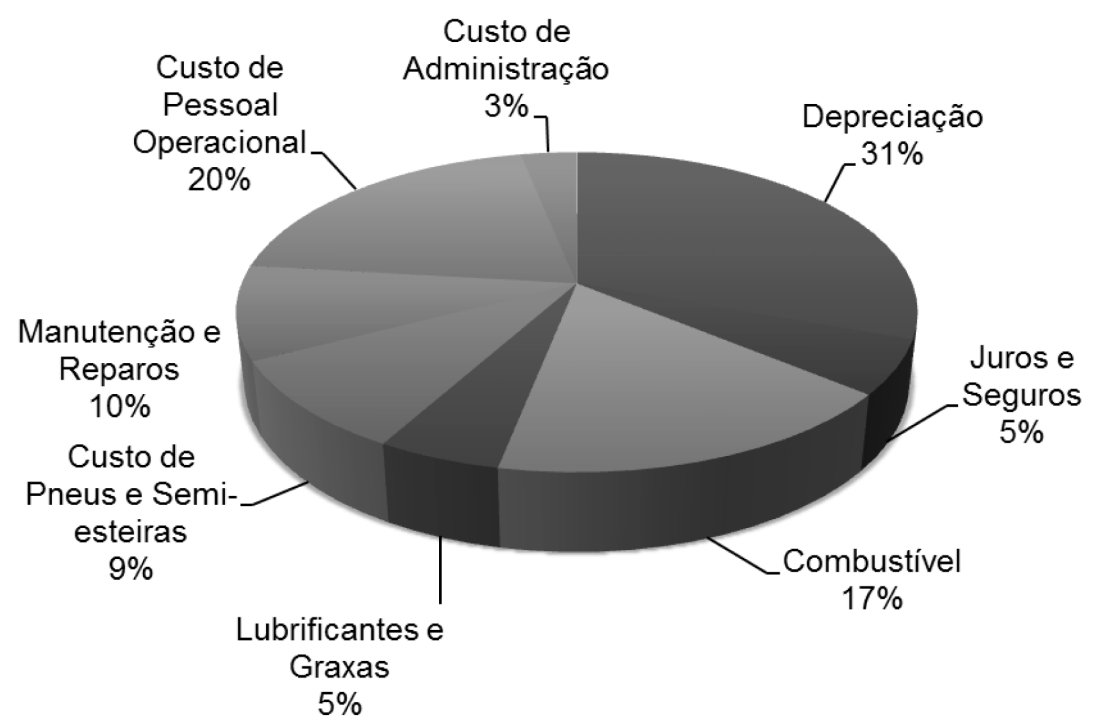

Figura 5. Composição percentual do custo operacional do forwarder.

Figure 5. Percent composition of the operational cost of the forwarder.

Considerado a produtividade operacional efetiva, o custo de extração resultou em $\mathrm{R} \$ 11,74$ e R\$ 9,97 por metro cúbico de madeira com casca, numa distância média de extração de 100 metros nos modelos operacionais 1 e 2, respectivamente. Comparando os resultados entre os modelos, nota-se uma redução no custo de extração de $15 \%$ com a adoção do modelo de extração por sortimento, podendo ser adotado no futuro pela empresa em povoamentos submetidos ao regime de desbaste.

Portanto, ficou evidente que a extração da madeira por sortimento em cada ciclo operacional foi o procedimento operacional mais eficiente do ponto de vista técnico e econômico, devido à redução dos tempos das etapas de carregamento e descarregamento, possibilitando assim um ganho médio de produtividade e redução de custo da ordem de 15\% em relação ao modelo de extração tradicional.

\section{CONCLUSÕES}

O carregamento e descarregamento consumiram o maior tempo do ciclo operacional do forwarder em ambos os modelos de extração, sendo as etapas onde podem ser adotadas medidas visando à otimização da operação.

O modelo de extração proposto permitiu uma redução significativa do tempo total do ciclo operacional do forwarder, ocasionado pelo menor tempo consumido no carregamento e descarregamento da madeira.

O modelo proposto de extração da madeira com separação dos sortimentos de toras permitiu um aumento de produtividade e redução de custo da ordem de $15 \%$, demostrando ser o procedimento operacional mais viável técnica e economicamente a ser adotado em povoamentos de pinus submetido ao primeiro desbaste.

\section{REFERÊNCIAS BIBLIOGRÁFICAS}

BARNES, R. M. Estudo de movimentos e de tempos - projeto e medida do trabalho. 6.ed. São Paulo: E. Blucher, 1977. $635 \mathrm{p}$.

BELBO, $\mathrm{H}$. Whole tree harvesting in early thinnings and landscape management. In: SUADICANI, K.; TALBOT, B. The Nnordic-Baltic conference on forest operations, Hørsholm: University of Copenhagen, 2008. p. 26.

DAVEL, M. Manejo de plantaciones: Boletin Técnico. Argentina: Centro de Investigación y Extensión Forestal Andino Patagónico, Universidad Nacional de la Patagonia, 2009. 16 p. 
Lopes et al. - Efeito do sortimento da madeira na produtividade

e custo do forwarder no desbaste comercial de Pinus taeda

FINGER, C. A.; SCHNEIDER, P. R. Determinação do peso do desbaste para florestas de Eucalyptus grandis Hill Ex Maiden, com base no Índice de Espaçamento Relativo. Ciência Florestal, Santa Maria, v. 9, n. 1, p. 79-87, 1999.

LAGESON, H. Effects of thinning type on the harvester productivity and on the residual stand. Internacional Journal of Forest Engineering, Umeå, v. 8, n. 2, p. 7-14, 1997.

LAMPRECH, H. Silvicultura nos trópicos: ecossistemas florestais e respectivas espécies arbóreas - possibilidade e métodos de aproveitamento sustentado. Eschborn: GTZ, 1990. 343 p.

LOPES, E. S. Aplicação do programa SNAP III (Scheduling and Network Analysis Program) no planejamento da colheita e do transporte florestal. 2001. 150 p. Tese (Doutorado) - Universidade Federal de Viçosa. Viçosa, 2001.

MALINOVSKI, R. A.; MALINOVSKI, R. A.; MALINOVSKI, J. R.; YAMAJI, F. M. Análise das variáveis de influência na produtividade das máquinas de colheita de madeira em função das características físicas do terreno, do povoamento e do planejamento operacional florestal. Floresta, Curitiba, v. 36, n. 2, p. 169-182, 2006.

MEDERSKI, P. A. Comparison of harvesting productivity and costs in thinning operations with and without Midfield. Forest Ecology and Mangement, Amsterdam, v. 224, n. 3, p. 286-296, 2006.

MINETTE, L. J.; MOREIRA, F. M. T.; SOUZA, A. P.; MACHADO, C. C.; SILVA, K. R. Análise técnica e econômica do forwarder em três subsistemas de colheita em florestas de eucalipto. Revista Árvore, Viçosa, v. 28, n. 1, p. 91-297, 2004.

MIYATA, E. S. Determining fixed and operating costs of logging equipament. Washington: USDA Forest Service, 1980. 16 p. (NC General Technical Report, 55)

OLIVEIRA, D.; LOPES, E.; FIEDLER, N. Avaliação Técnica e Econômica do Forwarder na Extração de Toras de Pinus. Scientia Forestalis, Piracicaba, v. 37, n. 84, p. 525-533, 2009.

RIBEIRO, N.; SITOE, A.; GUEDES, B.; STAISS, C. Manual de silvicultura tropical. Maputo: Universidade Eduardo Mondlane, 2002. 123 p.

SEIXAS, F.; CASTRO, G. P. Extração. In: MACHADO, C. C. Colheita florestal. 3.ed. Viçosa: UFV, 2014. p. 106177.

SILVA, E.; MACHADO, C.; MINETTE, L.; SOUZA, P.; FERNANDES, H.; SILVA, M.; JACOVINE, L. Avaliação técnica e econômica do corte mecanizado de Pinus sp. com harvester. Revista Árvore, Viçosa, v. 34, n. 4, p. 745-753, 2010.

SILVA, J. R.; FENNER, P. T. Desempenho de Tractor Florestal Transportador Autocarregável ("Forwarder"). Silva Lusitana, Lisboa, v. 17, n. 1, p. 97-108, 2009.

SIMÕES, D.; FENNER, P. T.; ESPERANCINI, M. S. T. Avaliação técnica e econômica da colheita de florestas de eucalipto com harvester. Scientia Forestalis, Piracicaba, v. 38, n. 88, p. 611-618. 2010.

SPINELLI, R.; NATI, C. A Low-Investment fully mechanised operation for pure selection thinning of pine plantations. Croation Journal of Forest Engineering, v. 2, n. 30, p. 89-97, 2009.

SPINELLI, R. Harvesting of thinnings. Florence: National Council for Research, Timber and Tree Institute, 2004. 6 p.

WADSWORTH, F. Producción forestal para América Tropical. San José: USDA FOREST SERVICE, 2000. 461 p. (Manual de Agricultura, 710-S)

Recebido em 02/10/2014

Aceito para publicação em 30/07/2015 